1 Hacettepe Journal of Mathematics and Statistics

h Volume 48 (3) (2019), 883-896

Research ARticle

\title{
Risk adjusted hospital mortality prediction model: a case study in a Turkish training and research hospital
}

\author{
Fatma Güntürkün*†'(D) and Özgül Vupa Çilengiroğlu ${ }^{\ddagger}$ (i)
}

\begin{abstract}
In today's world, health organizations give much importance to quality and patient safety. To this end, conservation of life and prevention of excessive deaths are one of the vital objectives for health services in all countries [22]. Although the main function of hospitals is to save lives, there is a little attention to hospital mortality. In this context; generating reliable mortality statistics and then monitoring them is a prerequisite for improvement in care and development in patient safety. In this study; a risk adjusted hospital mortality prediction model is developed by using some popular data mining techniques; logistic regression, decision trees, random forests and artificial neural networks. The data from 30182 inpatients of one of the Turkish training and research hospitals with 1155 beds is used. The data is collected from inpatients whose discharge period is January to November in 2014. At the end, the performance of these approaches are compared.
\end{abstract}

Keywords: Risk adjusted mortality, Logistic regression, Decision trees, Random forest, Artificial neural networks

Mathematics Subject Classification (2010): 62P10

Received: 06.12.2017 Accepted : 29.06.2018 Doi: 10.15672/HJMS.2018.615

* Dokuz Eylül University, Izmir, TURKEY, Email: fatmaaydinlik@gmail.com

${ }^{\dagger}$ Corresponding Author.

$\ddagger$ Department of Statistics, Faculty of Science, Dokuz Eylül University, Izmir, TURKEY, Email: ozgul.vupa@deu.edu.tr 


\section{Introduction}

Florence Nightingale was one of the important people to detect the importance of measuring survival rates in the late 1850's. She highlighted the variation of hospital death rates in London and pointed out that these variations were not just owing to the differences in the health of local populations but also due to the differences in the quality of medical care at different hospitals. In this context; generating reliable mortality statistics and then monitoring them are a pre-requisite for improvement in care and development in patient safety [9].

One basic way of constructing mortality statistics is based on deaths in whole populations. Since there is a wide interest on excessive deaths, there is also need for mortality measures based on deaths in hospitals only. We can measure hospital mortality in three ways: (I) examining case notes of all deaths, (II) crude mortality rates and (III) risk adjusted mortality measures [9].

\section{Risk adjusted mortality measures}

The number of factors can influence health, so when calculating the risk of death we should consider several factors like demographic properties, diagnostics and procedural information. Several methods, all of which are subjective for measuring risk adjusted mortality in hospitals exist in literature. If these measures can be used accurately, they provide health systems to detect the areas for improvement [23].

Four risk adjusted measures have been examined in the scope of this study which are; (I) Risk Adjusted Mortality Index (RAMI), (II) Hospital Standardized Mortality Ratio (HSMR), (III) Scottish HSMR and (IV) Summary Hospital-level Mortality Indicator (SHMI). For these measures the number of observed deaths is compared to the number of expected deaths which is predicted by a specific model.

2.1. Risk adjusted mortality index. RAMI was constructed by Susan DesHarnais and her friends in 1988 [10]. Aim of the measure is to estimate the risk of death during a hospital stay for specific diagnoses and procedures. It provides health systems to investigate deaths and make improvements over time. It is used in Wales to monitor hospital mortality at a national and organisational level. It is calculated by a private company, Caspe Healthcare Knowledge Systems (CHKS). When constructing the model, they used diagnoses related group (DRG) database in a cohort of 300 hospitals for 1983 and 1984. They regrouped DRGs and developed models for each of them. They used logistic regression (LR) model for $64 \mathrm{DRG}$ clusters with cluster death rates $5 \%$ or higher and the contingency table model for the other DRG clusters.

2.2. Hospital standardized mortality ratio. HSMR was constructed by Professor Sir Brian Jarman who is the director of the Dr Foster Unit at Imperial College in 2001. In that year, they published the first national publication of standardized hospital death rates in the world named Hospital Guide [11]. Thenceforth, it has been regularly produced by Dr Foster Intelligence each year. Now, it is used by several countries such as US, Canada, the Netherlands etc. [21, 17].

The HSMR is a useful indicator of patient safety which provides hospitals to investigate deaths and make improvements over time. The Institute for Healthcare Improvement (IHI) in USA, has started to use HSMR in their organizations to improve the safety of patients. The methods used for HRSM in each country are similar, but it can be modified based on the national mortality experience. For instance, the diagnosis groups involved can be changed from country to country [23]. 
2.3. Scottish hospital standardized mortality ratio. The Scottish Patient Safety Programme (SPSP) has been started to decrease hospital mortality in 2008. Information Services Division (ISD) has developed and began to publish HSMR for all Scottish hospitals participating in the SPSP in early 2008 to monitor their progress on decreasing hospital mortality over time. The Scottish Government established the Healthcare Quality Strategy for National Health Services (NHS) Scotland consisted of six dimensions of care as person-centred, safe, effective, efficient, equitable and timely. They used 12 quality outcome measures, one of which is HSMR, to monitor processes to determine whether they achieve their goals or not [15].

2.4. Summary hospital-level mortality indicator. The HRSM is criticized in certain aspects such as application of it as a measure of overall quality of care, having been subject to little empirical evaluation, not including all inhospital deaths, not regarding all patients' comorbidities, not taking the deaths after discharge, not considering readmissions so it may be possible to double count one patient death. Therefore, The Health Social Care Information Centre (HSCIC) developed a new methodology based on HSMR in 2011 [7]. SHMI covers $100 \%$ of deaths in hospital and up to 30 days after discharge from hospitals (excluding deaths on arrival and still births).

2.5. Comparison of risk adjusted mortality measures. RAMI and HSMR consider inpatient and day case deaths in hospitals whereas SHSMR includes patients who died within 30 days from hospital admission, both deaths that occurred in the community and in hospital. But, it excludes patients who die in hospital after 30 days from admission. HSMR excludes episodes with missing age, sex, type of admission and year of discharge and SHSMR excludes episodes with missing sex. On the other hand, there is no exclusion of episodes in SHMI. The other differences/similarities between the risk adjusted measures were summarized in Appendix 1. If the desired information of measures couldn't be reached then the related part in the table is left empty.

Risk factors involved in the measures are demonstrated in Appendix 2. Leading risk factor is the patients' primary diagnoses. Since the number of diagnoses is too many, a need arose to group them. 26 diagnosis groups including all diagnoses were developed for Scottish HRSM. Other measures use diagnoses categories of Clinical Classifications Software (CCS). CCS was developed by using Agency for Healthcare Research and Quality Healthcare Cost and Utilization Project (HCUP) which is a family of databases sponsored by Agency for Healthcare Research and Quality (AHRQ). It combines huge number of patient diagnoses and procedures into a manageable number of categories. So, researchers, and policy makers can easily understand several outcomes of the diseases like death, cost, patterns etc. [1]. CCS includes two classification systems, single-level (260 categories) and multi-level. ICD 10 codes for each CCS cluster which can be reached from the web site [2]. While HSMR is focused on 56 CCS categories, SHMI re-groupes 260 CCS groups to reach 140 diagnoses groups.

The other risk factor used in these measures is the Charlson comorbidity index which is computed by using the additional diagnoses of the patient. Charlson and his friends developed a scoring system considering the number and seriousness of comorbidities in 1987. This scoring system considers 17 different comorbidity groups such as acute myocardial infarction (I21, I22, I23, I252, I258), diabetes (E101, E105, E106, E108 etc.), renal disease (I12, I13, N01, N03, N052-N056 etc.) [8]. Except RAMI, this score were used in all measures. The most serious seconder diagnose was considered in RAMI instead of this score. Another risk factor Carstairs index for each output area was derived from 2001 census within the United Kingdom. It was computed by normalising the unemployment, households without a car or van, households with over one persons per room and low social class variables [4]. 
2.6. Interpretation of risk adjusted mortality measures. Risk adjusted mortality measures should be considered as motivation indicators. They provide us to show how successful hospitals are in reducing inpatient death. They shouldn't be interpreted as the number of avoidable deaths instead they should be described as above expected range [16]. In literature, they are consireded as smoke alarm. And, if there is a smoke alarm, we can not ignore it but still it does not always mean there is a fire. Some of the possible reasons for the changes on the risk adjusted mortality measures are demonstrated below:

- Improvements in the quality of care and treatment

- Changes to the completeness and accuracy of clinical coding

- Under-reporting of comorbidities

- Inappropriate and/or untimely care

- Poor medicines management

- Hospital acquired infections [23]

Risk adjusted measures are demonstrated on funnel plots commonly. In these plots $\mathrm{y}$-axis shows the value of the risk adjusted measure and the $\mathrm{x}$-axis presents the expected number of deaths. Upper and lower control limits showing us the random variation in data also appear in the plot. Points outside the control limits are considered not to be caused by chance. The Hospital Guide publishes the names of outlier hospitals annually [11].

\section{Materials and methods}

Data mining (DM) techniques were applied for predicting mortality. DM is defined as 'the process of exploration and analysis, by automatic or semiautomatic means of large quantities of data in order to discover meaningful patterns and rules' [5]. In the scope of this study first, a traditional statistical technique that classifies observations with categorical response variables such as the logistic regression modelling was implemented. Second, the tree shaped structures, decision trees (DT), were applied. Construction of these trees is simple and the results can easily be understood by the users. There are several DT algorithms in the literature such as CART [6], CHAID [18] etc. In this study; CHAID, selecting optimal splits by using chi-squared test and developing trees with more than two branches were used in the prediction models. Third, one of the ensemble methods called random forest (RF) was applied. It generates different training sets by resampling the dataset. Then, it creates models from each training set. When determining the class of a new tuple, it aggregates predictions of the derived models. Finally, artificial neural networks (ANN) were applied. This methodology learns from historical data as humans do.

3.1. Data collection and preprocessing. The analyses are derived from the records of one of the Turkish Training and Research Hospitals' inpatients and day case patients for the discharge period January to September of 2014. We disregarded the patients transferred to another hospital or quit the treatment. The data such as primary diagnoses, comorbidities, sex, age of the patients are gathered from DRG database. The number of emergency admissions of patients in the last 12 months which are collected from the hospital information management system is added to this data.

After collecting the data, we prepared it for the analyses. First of all, we transformed ICD 10 codes of the diagnoses into the CCS. Later, it is converted to the diagnoses categories of the risk adjusted measures that examined in the scope of this study. And, by using the supporting diagnoses we calculated Charson comorbidity score of these patients by using the weights determined by the study done by Aylin and his friends [4]. Then we convert our data to the continuous stay. If a patient discharged from one of 
the ward and admitted another ward within a 24 hour period we considered these stays as a continuous stay. We combined the data of these kind of patients. When combining the data we took the data of first stay of patients for input variables and the data of the last stay for output variables. Then, we divided the data into quarters according to the discharge dates. We only take the last continuous stay of the patients to the analyses to make our data patient based. As a result, our data includes seven risk factors which are age, sex, number emergency admissions in the previous 12 month period, source of admission, primary diagnoses, comorbidity score and admission month. 30182 records were used in the analyses 1006 of which belong to the patients that died.

To cross validate the model, we divided the data set into two parts which were selected randomly without replacement both from the alive and dead patients. When modelling the data we used \%70 (21113) of the data set as training data and the other part \%30 (9069) as test data. On the other hand, we faced with unbalanced data problem in our data. In unbalanced data one of the classes is represented by a very small number compared to the other class [13]. To change the unbalanced data to a balanced one, the resampling methodology is used. Resampling methodology can be classified into three groups: (I) random undersampling, (II) random oversampling, (III) hybrid methods [20]. In this study, we used random oversampling to handle with unbalanced data. We repeated our dead patient's data up to make our data balanced and we reached 57344 patient records.

\section{Results}

As part of the analyses, first the cross analyses are conducted to investigate the effects of risk factors on hospital mortality. Considering the mortality rates in age groups, it is decided to address the age in three groups as 0-39, 40-64 and 65-and-above. While mortality occurs in $3.1 \%$ of the female patients, this ratio is $3.6 \%$ in males. When the number of emergency admissions are examined against mortality rate in the last 12 months, it is decided to group this variable as $0,1-6$ and 7 -and-above. The mortality rate in emergency patients is $8.6 \%$ whereas this rate is $2.2 \%$ for other patients. When the comorbidity disease scores are examined against mortality rates, it is decided to group the scores as 0, 1-2 and 3-and-above. When we examine the month of admission against mortality rate, it is seen that the mortality rate is higher in November and December compared to other months of the year. Therefore, the month of admission variable is grouped into two, one being November and December and the other being the remainder. When the disease diagnosis groups are examined, it is seen that CCS comprises of 260, HSMR of 56, SHSMR of 26 and SHMI comprises of 140 categories. As the present data contains fewer numbers of mortality and there is not enough mortality in each diagnosis group, it is decided to use the diagnosis groups defined in SHSMR [15].

4.1. Setting up risk adjusted mortality rate estimation models. Models are set up using LR, DT, RF and ANN, and their performances are evaluated on training and test data. In the DT model, in order to avoid excessive training, the minimum number of observations in the leaf nodes is limited to 50. The number of levels in the DT is seven, and 177 rules are formed. In the ANN model a perceptron structure, which had a hidden layer comprising of 51 operation units, is used.

In the performance evaluation, precision which indicates percentage of the true positives and specificity which indicates the percentage of true negatives are calculated. In addition, accuracy which indicates the approximation of the measurements to the real value and the area under curve (AUC) are calculated which indicates the area under the operation characteristic curve showing the true positive percentage against false positive 
percentage for different threshold values. The performances obtained from the models are presented in Figure 1.
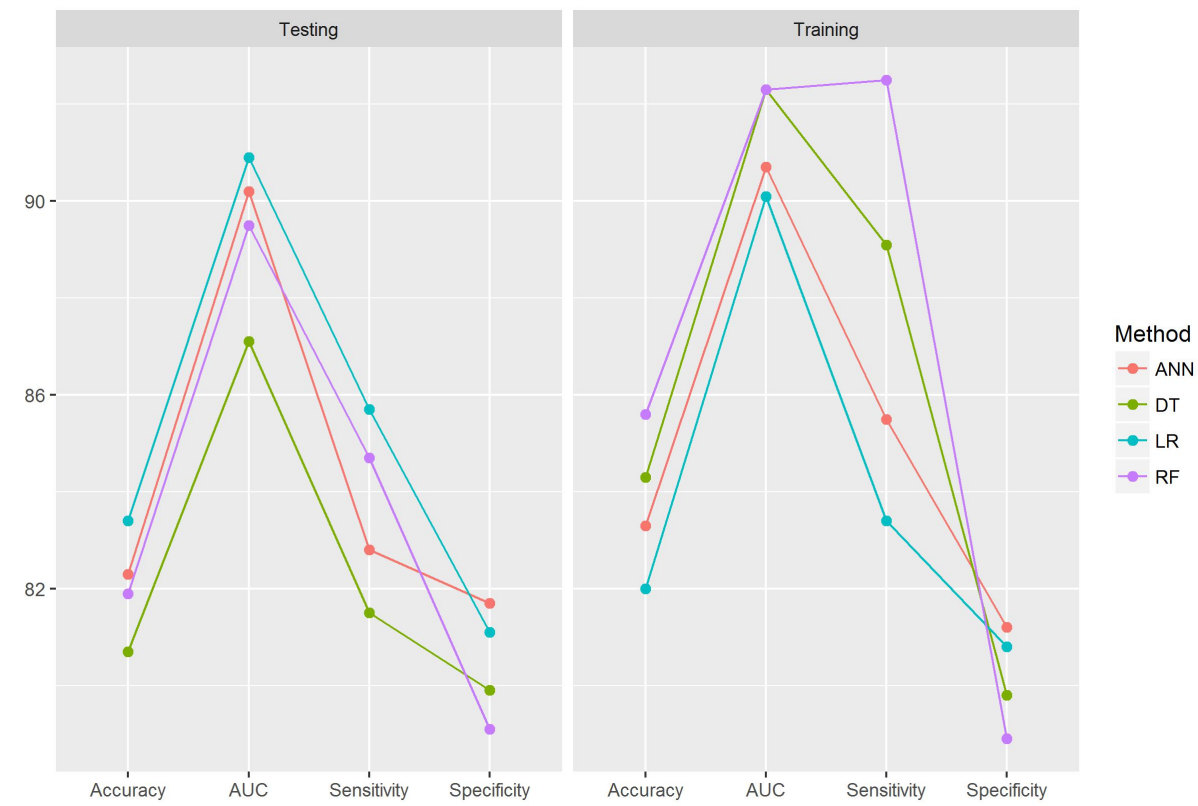

Figure 1. The performance measurements of the hospital mortality rate estimation

When evaluating the performances of different models, the performance of the model on the independent data set, i.e. the test data, is more important. In this respect, it can be seen that the results obtained from the LR and ANN models are close to each other. Since LR is easier to understand and to interpret by the users, compared to the ANN model, the results obtained from the LR model are used to calculate the standardized mortality ratios. When the models in the literature are examined, it is seen that LR method is used in all measurements except for the SHSMR.

The model obtained from the LR method is presented in Appendix 3. First, the model agreement is determined considering the Cox \& Snell $R^{2}$ and Nagelkerke $R^{2}$ statistics values. These values show the variance amount produced by the $L R$ model and 1.00 shows the perfect model agreement. Therefore, greater values correspond to a better model agreement [14]. Since, Cox \& Snell $R^{2}$ never reaches 1, and therefore it is not easy to interpret, the Nagelkerke $R^{2}$ - which is the modified version of it and greater than this coefficient - is calculated $[14,12,3]$. In this study, the Nagelkerke $R^{2}$ statistics value is 0.603 , whereas Cox \& Snell $R^{2}$ is found to be 0.452 .

For the sex variable in the LR model, the Wald test statistics score (31.98) is high, the $p$ value $(0.00<0.05)$ is low, the odds ratio $(1.18)$ is found interpretable and the pertaining confidence interval $(1.11-1.12)$ is statistically significant since it does not contain the value 1 . This significance is interpreted as being male increased the chance of mortality by approximately 1.2 times, when compared to being female. In a similar fashion; the Wald test scores for mode of intervention, age, the number of emergency admittances in the last 12 months, the month of admission, the comorbidity disease score and diagnosis group 
are high; $\mathrm{p}$ values low, odds ratios interpretable and the pertaining confidence intervals are statistically significant. Accordingly, the chance of mortality for patients admitted to emergency service is found 6.7 times higher than the ones which have not been admitted to emergency. When the age groups are considered, it is found that the rate of mortality in older ages is higher when compared to the patients under 40 years of age. In this respect, the mortality rate of 65 -and-above patients is 4.4 times higher than patients under 40 years of age, whereas it is 2.1 times higher than patients in the 40-64 age group. When the number of emergency admissions in the last 12 months is examined, it is found that the patients, who had been admitted to emergency less than 6 times in the last 12 months, have a mortality rate 3.4 times higher than the ones who had not been admitted to emergency. A similar situation is observed in patients who had been admitted to emergency for more than 7 times. It is also found that, the mortality rate in patients, who had been admitted to hospitals in November and December, is 2.2 times higher when compared to other months. It is determined statistically that patients with a comorbidity disease score 2 and below have mortality rates 3.5 times higher than patients without any comorbidity diseases. This score is found 12.6 times higher in patients with comorbidity disease score 3 and higher. When the diagnosis groups are examined in 24 categories, the "cerebrovascular1" category comprising diagnoses such as cerebral infarction (I63), acute myocarditis (I40), artery embolism and thrombosis (I74) is taken as the reference group. Accordingly, Wald test statistics score, $p$ value, odds ratio and pertaining confidence intervals for 23 categories are examined. Considering these examinations, it was found that patients in the "malig2" group - comprising of diagnoses for malignant neoplasm of hypopharynx (C13), malignant neoplasm of pancreas (C25), malignant neoplasm of stomach (C16) and malignant neoplasm of brain (C71) - have mortality rates 10.1 times higher than the patients in the "cerebrovascular1". Similarly, the mortality rate for the patients in "KVS2" diagnosis group - which includes disease diagnoses such as rheumatic aortic valve (I06), pulmonary embolism (I26), acute and subacute endocarditis (I33) is found 4.4 times higher than patients in the "cerebrovascular1" group. On the other hand, the mortality rate for "cerebrovascular1" patients is found $(1 / 0.182)=5.494$ ) approximately 5.5 times higher than patients in the "gastro3" group which includes diagnoses such as peritonitis (K65), hepatic failure not elsewhere classified (K72), ascites (R18).

4.2. Comparison of crude mortality rates and standardized mortality ratios. The results obtained in the study by measuring the crude mortality rates and the standardized mortality ratios obtained in the three months periods are presented in Figure 2. The crude mortality rate is obtained by dividing the number of deaths to total number of patients. The calculation of standardized mortality ratio is conducted by dividing the number of deaths to the total of mortality probability obtained from the LR method.

When the crude mortality rates are considered, the highest mortality rate of the hospital occurs between January and March, while the lowest rate occurs between July and September. As for the standardized mortality ratios, it is seen that the actual number of deaths in the hospital exceeded the expected mortality ratio between July and September. When a performance evaluation is conducted with regard to crude mortality rates, it is seen that the hospital had presented the worst performance between January and March; whereas when the same evaluation is conducted using standardized mortality ratios, it is seen that the hospital had performed the worst between July and September. The structure of the hospital is also important in the deaths that occur in the hospital. There is finding in the literature that there is a correlation between mortality and number of physicians, nurses and even cleaning staff per 100 beds [19]. In 


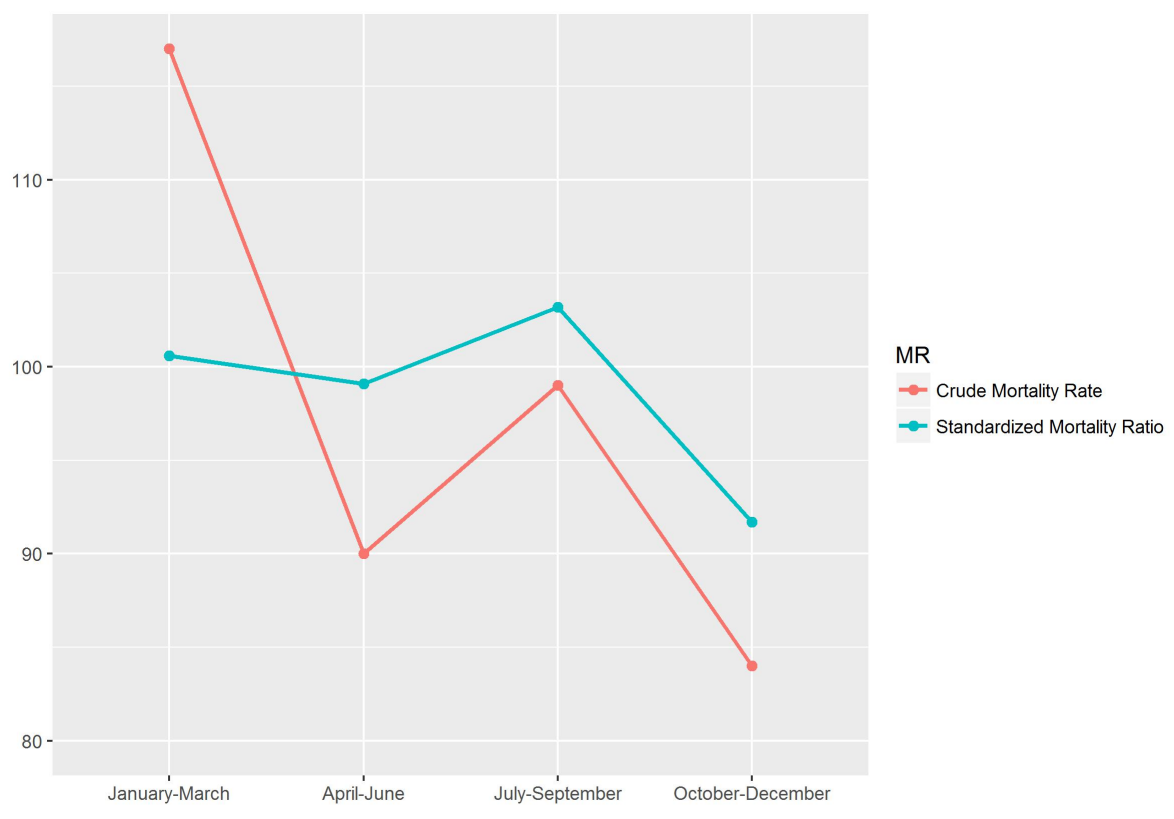

Figure 2. Comparison of crude mortality rates and standardized mortality ratios

this respect, the underperformance in summer period can be explained by the change in the structure of the hospital due to holiday period.

The crude mortality rates are calculated directly over the number of deaths, without considering the case mix approach. Standardized mortality ratios, on the other hand, a case mix approach is used and the expected mortality rates and actual mortality rates of the hospitals are compared. Thus, the performance evaluation of the hospitals can be conducted objectively. Similarly, the performance values presented in Figure 2 could belong to different hospitals, instead of different periods of the year. In such a case, a performance evaluation on the crude mortality rates would yield a misevaluation by indicating hospitals with higher actual performance as low, and hospitals with lower actual performance as high. Indeed, when the structures of the hospitals are considered, there are hospitals which include a palliative care centre, and hospitals which provide service to more complicated diseases compared to counterparts due to its geographical status and structure. In these hospitals, no matter how high the service quality is, the crude mortality rates would be higher compared to another hospital with a similar capacity. Therefore, it is of great significance to use risk adjusted measurement methods in evaluating hospital mortality.

Another evaluation that could be performed using the standardized mortality ratios is to monitor the performance in different diagnosis groups with regard to periods of the year. The standardized mortality ratios for 24 diagnosis groups, calculated for three months periods, are presented in Appendix 4. Accordingly, actual mortality for "Metabolic" and "Respiratory1" diagnosis groups remained higher than expected mortality in the July-December period; whereas actual mortality for "Gastro1" diagnosis group remained higher than expected mortality in the January-June period. In "CVS1" diagnosis 
group expected mortality remained mostly lower than expected; while it remained mostly higher in "CVS2" diagnosis group.

\section{Conclusion}

Nowadays, it comes into prominence using performance measurements in service sector as well as industry. For the leading one of these organizations, hospitals, this case is also imminent. Indicators such as infection rates, waiting times, and readmission rates can be used to evaluate performance of hospitals. Since the main aim of the hospitals is to save life, measuring and monitoring mortality rates has a special importance in these indicators. In this respect, using standardized mortality ratios when determining whether the number of deaths are high or low can be more objective since it considers different risk factors.

In this study, first of all, risk adjusted mortality prediction models represented in literature are examined in terms of their risk factors, focused patients etc. Later, the data of 30182 inpatients of one of the Turkish Training and Research Hospitals whose discharge period is January to November in 2014 was gathered. After collecting the data, we prepared it for the analyses towards literature and developed models by using different popular data mining techniques. The developed models are evaluated by using different performance criteria and it was seen that logistic regression method gives better results compared to the other methods.

\section{References}

[1] Agency for Healthcare Research and Quality. Healthcare Cost and Utilization Project (HCUP) - Clinical Classifications Software (CCS), 2013

[2] Agency for Healthcare Research and Quality. ICD10-CCS. http://www.ahrq.gov/downloads/pub/ccs/icd10ccs.txt. Accessed 2014.

[3] Allison P. What is the Best R-Squared for Logistic Regression, http://statisticalhorizons.com/r2logistic, Published 2013, Accessed 2015.

[4] Aylin P, Bottle A, Jen M, Middleton S. HSMR Mortality Indicators. Dr Foster Unit at Imperial College; 2010.

[5] Berry M, Linoff G. Mastering Data Mining: The Art and Science of Customer Relationship Management (New York: Wiley Computer Pub; 2000).

[6] Breiman L, Friedman JH, Olshen RA, Stone CJ. Classification and Regression Trees (New York: Chapman and Hall; 1984).

[7] Campbell MJ, Jacques RM, Fotheringham J, Pearson T, Maheswaran R, Nicholl J. Developing A Summary Hospital Mortality Index: Retrospective Analysis in English Hospitals Over Five Years, BMJ 344, 2012.

[8] Charlson M, Pompei P, Ales K, MacKenzie R. A New Method of Classifying Prognostic Comorbidity in Longitudinal Studies: Development and Validation, Journal of Chronic Diseases 40 (5), 373-383, 1987.

[9] Daniels J, Clarke L, Swain K, Studley R. Mortality Statistics in Wales., Statistical Article Erthygl Ystadegol, 2013.

[10] Desharnais S, Chesney JD, Wroblewski RT, Fleming ST, Mcmahon LF The Risk-Adjusted Mortality Index: A New Measure of Hospital Performance, Medical Care. 1129-1148, 1988.

[11] Dr Foster Intelligence. Understanding HSMRs: A Toolkit on Hospital Standardized Mortality Ratios, London, 2012.

[12] Field A. Discovering Statistics Using SPSS (2nd ed.), (London: Sage, 2005).

[13] Garcia V, Sanchez JS, Mollineda RA On The Effectiveness of Preprocessing Methods When Dealing With Different Levels of Class Imbalance, Knowledge Based Systems 25, 13-21, 2012.

[14] Hair JF, Black WC, Babin B, Anderson RE, Tatham RL. Multivariate Data Analysis (6th ed) (Upper Saddle River, NJ: Prentice-Hall; 2006). 
[15] Information Services Division (ISD). ISD. Hospital Standardized Mortality Ratios Quarterly HSMR Release, 2013.

[16] Jarman B. In Defence of the Hospital Standardized Mortality Ratio, Healthcare Papers, $37-42,2008$

[17] Jarman B, Pieter D, van der Veen A, Kool RB, Aylin P, Bottle A, Jones S. The Hospital Standardized Mortality Ratio: A Powerful Tool for Dutch Hospitals to Assess Their Quality of Care, Quality Safety Health Care, 9-13, 2010

[18] Kass, GV. An Exploratory Technique For Investigating Large Quantities of Categorical Data, 29, 1980.

[19] NHS. Understanding and Interpreting Mortality Data, http://www.cwmtafuhb.wales.nhs.uk/opendoc/223642, Accessed 2013.

[20] Satyasree KPNV, Murthy JVR An Exhaustive Literature Review on Class Imbalance Problem, International Journal of Emerging Trends \& Technology in Computer Science, 2, 109$118,2013$.

[21] Wen E, Sandoval C, Zelmer J, Webster G Understanding and Using the Hospital Standardized Mortality Ratio in Canada: Challenges and Opportunities., Healthcare Papers, 26-36, 2008.

[22] Whalley L. Report from the Steering Group for the National Review of the Hospital Standardized Mortality Ratio, NHS Information Centre for Health and Social Care, 2010.

[23] Williams L. and Davidge M. 1000 Lives. A Guide to Measuring Mortality., http://www.1000livesplus.wales.nhs.uk Published 2010, Accessed 2014. 


\section{Appendices}

\section{Appendix 1: Comparison of risk adjusted mortality measures}

\begin{tabular}{|c|c|c|c|c|}
\hline & RAMI & HSMR & SHSMR & SHMI \\
\hline Year Developed & 1988 & 2001 & 2008 & 2011 \\
\hline Author & CHKS & $\begin{array}{l}\text { Dr Foster Unit } \\
\text { at Imperial College }\end{array}$ & ISD & HSCIC \\
\hline Publication period & & $\begin{array}{l}\text { Annually publish } \\
\text { hospital guide }\end{array}$ & Quarterly & Quarterly \\
\hline $\begin{array}{l}\text { Time period for con- } \\
\text { structed model }\end{array}$ & & & $\begin{array}{l}\text { October } 2006- \\
\text { September } 2007\end{array}$ & $\begin{array}{ll}2008 / 2009 & \text { to } \\
2010 / 2011 & \\
\end{array}$ \\
\hline $\begin{array}{l}\text { Databases that they } \\
\text { used }\end{array}$ & $\begin{array}{l}\text { CHKS } \\
\text { system }\end{array}$ & HES, SUS, CDS & $\begin{array}{l}\text { SMR01 \& NRS } \\
\text { death records }\end{array}$ & \\
\hline $\begin{array}{l}\text { Coverage of in- } \\
\text { hospital death }\end{array}$ & $86 \%$ & $83 \%$ & & $100 \%$ \\
\hline Method & $\mathrm{LR}$ & $\mathrm{LR}$ & DT (CHAID) & $\mathrm{LR}$ \\
\hline $\begin{array}{l}\text { Transfer patients } \\
\text { deaths }\end{array}$ & & $\begin{array}{l}\text { All hospitals involved } \\
\text { in admission }\end{array}$ & $\begin{array}{l}\text { Last admitting } \\
\text { hospital }\end{array}$ & $\begin{array}{l}\text { Last admit- } \\
\text { ting hospital }\end{array}$ \\
\hline $\begin{array}{l}\text { Zero length emer- } \\
\text { gency admissions }\end{array}$ & $\mathrm{X}$ & $\mathrm{X}$ & $\checkmark$ & \\
\hline Day cases & & $\mathrm{X}$ & $\checkmark$ & $\mathrm{X}$ \\
\hline Still-born babies & & $\mathrm{X}$ & $\mathrm{X}$ & $\mathrm{X}$ \\
\hline $\begin{array}{l}\text { Un-coded clinical ac- } \\
\text { tivity }\end{array}$ & & $\checkmark$ & $\mathrm{X}$ & $\mathrm{X}$ \\
\hline Mental health & $\mathrm{X}$ & & $\mathrm{X}$ & \\
\hline Obstetrics & & & $\mathrm{X}$ & \\
\hline Maternity & $\mathrm{X}$ & & $\mathrm{X}$ & \\
\hline Live births & $\mathrm{X}$ & & $\mathrm{X}$ & \\
\hline Death on arrival & & & $\checkmark$ & $\mathrm{X}$ \\
\hline Palliative care cases & $\mathrm{X}$ & $\checkmark$ & $\mathrm{X}$ & $\checkmark$ \\
\hline
\end{tabular}


894

\section{Appendix 2: Risk factors in hospital mortality prediction models}

\begin{tabular}{|c|c|c|c|c|}
\hline & RAMI & HSMR & SHSMR & SHMI \\
\hline Primary Diagnose & $\checkmark$ & $\checkmark$ & $\checkmark$ & $\checkmark$ \\
\hline Age & $\checkmark$ & $\checkmark$ & $\checkmark$ & $\checkmark$ \\
\hline Sex & $\checkmark$ & $\checkmark$ & $\checkmark$ & $\checkmark$ \\
\hline $\begin{array}{l}\text { Type of admission (emergency / elective / miss- } \\
\text { ing) }\end{array}$ & & $\checkmark$ & $\checkmark$ & $\checkmark$ \\
\hline Year of discharge & & $\checkmark$ & & $\checkmark$ \\
\hline Year of admission & & & $\checkmark$ & $\checkmark$ \\
\hline Month of admission & & $\checkmark$ & $\checkmark$ & \\
\hline $\begin{array}{l}\text { Number of emergency admissions in previous } 12 \\
\text { months }\end{array}$ & $\mathrm{X}$ & $\checkmark$ & $\checkmark$ & $\checkmark$ \\
\hline Ethnicity & & $\checkmark$ & & $\checkmark$ \\
\hline Source of admission & & $\checkmark$ & $\checkmark$ & $\checkmark$ \\
\hline Race & $\checkmark$ & & & \\
\hline Charlson comorbidity index & $\mathrm{X}$ & $\checkmark$ & $\checkmark$ & $\checkmark$ \\
\hline Deprivation & $\mathrm{X}$ & & & $\checkmark$ \\
\hline Specialty & & & $\checkmark$ & \\
\hline Interaction between age and comorbidity & & $\checkmark$ & & \\
\hline Interaction between age and deprivation score & & & & $\checkmark$ \\
\hline Interaction between age and admission source & & & & $\checkmark$ \\
\hline $\begin{array}{l}\text { Severity of prior morbidities in the previous } 12 \\
\text { months }\end{array}$ & & & $\checkmark$ & \\
\hline $\begin{array}{l}\text { Severity of prior morbidities in the previous } 5 \\
\text { years }\end{array}$ & & & $\checkmark$ & \\
\hline Seasonality & & & & $\checkmark$ \\
\hline Total number of previous complex admiss & & & & $\checkmark$ \\
\hline
\end{tabular}




\section{Appendix 3: Summary of logistic regression model}

\begin{tabular}{|c|c|c|c|c|c|c|c|c|}
\hline & B & S.E. & Wald & $\mathrm{df}$ & Sig. & $\operatorname{Exp}(B)$ & $\begin{array}{l}95 \% \mathrm{CI} \\
\text { Lower }\end{array}$ & Upper \\
\hline Sex (Man) & 0.165 & 0.029 & 31.984 & 1 & 0.000 & 1.179 & 1.114 & 1.249 \\
\hline $\begin{array}{l}\text { Source of admission (Emer- } \\
\text { gency) }\end{array}$ & 1.898 & 0.041 & 2146.768 & 1 & 0.000 & 6.672 & 6.157 & 7.230 \\
\hline Age Group & & & 1071.757 & 2 & 0.000 & & & \\
\hline Age Group (40-64) & 0.742 & 0.054 & 192.243 & 1 & 0.000 & 2.101 & 1.892 & 2.333 \\
\hline Age Group (65 and above) & 1.481 & 0.053 & 788.242 & 1 & 0.000 & 4.398 & 3.966 & 4.878 \\
\hline $\begin{array}{l}\text { Num of emergency admis- } \\
\text { sions in previous } 12 \text { months }\end{array}$ & & & 1081.068 & 2 & 0.000 & & & \\
\hline $\begin{array}{l}\text { Number of emergency ad- } \\
\text { missions in previous } 12 \\
\text { months (1-6) }\end{array}$ & 1.212 & 0.037 & 1063.385 & 1 & 0.000 & 3.361 & 3.125 & 3.615 \\
\hline $\begin{array}{l}\text { Number of emergency ad- } \\
\text { missions in previous } 12 \\
\text { months ( } 7 \text { and higher) }\end{array}$ & 1.238 & 0.102 & 146.248 & 1 & 0.000 & 3.449 & 2.822 & 4.216 \\
\hline $\begin{array}{l}\text { Admission Month } \\
\text { (November-December) }\end{array}$ & 0.777 & 0.063 & 152.083 & 1 & 0.000 & 2.174 & 1.922 & 2.460 \\
\hline Comorbidity score & & & 1913.478 & 2 & 0.000 & & & \\
\hline Comorbidity score (1-2) & 1.242 & 0.033 & 1406.505 & 1 & 0.000 & 3.464 & 3.246 & 3.696 \\
\hline $\begin{array}{l}\text { Comorbidity score (3 and } \\
\text { higher) }\end{array}$ & 2.536 & 0.095 & 716.826 & 1 & 0.000 & 12.631 & 10.490 & 15.207 \\
\hline Primary Diagnose Group & & & 5577.458 & 23 & 0.000 & & & \\
\hline Cerebrovasc2 & -1.969 & 0.081 & 590.718 & 1 & 0.000 & 0.140 & 0.119 & 0.164 \\
\hline CVS1 & 0.374 & 0.092 & 16.689 & 1 & 0.000 & 1.454 & 1.215 & 1.739 \\
\hline CVS2 & 1.490 & 0.104 & 205.040 & 1 & 0.000 & 4.436 & 3.617 & 5.439 \\
\hline CVS3 & 1.415 & 0.138 & 104.790 & 1 & 0.000 & 4.117 & 3.140 & 5.398 \\
\hline Gastro1 & -0.053 & 0.112 & 0.225 & 1 & 0.636 & 0.948 & 0.761 & 1.181 \\
\hline Gastro2 & -1.533 & 0.093 & 274.613 & 1 & 0.000 & 0.216 & 0.180 & 0.259 \\
\hline Gastro3 & -1.702 & 0.251 & 45.888 & 1 & 0.000 & 0.182 & 0.111 & 0.298 \\
\hline Haem & -1.749 & 0.135 & 168.946 & 1 & 0.000 & 0.174 & 0.134 & 0.227 \\
\hline Low risk & 0.147 & 0.126 & 1.350 & 1 & 0.245 & 1.158 & 0.904 & 1.483 \\
\hline Malig1 & 0.910 & 0.105 & 74.712 & 1 & 0.000 & 2.483 & 2.020 & 3.052 \\
\hline Malig2 & 2.313 & 0.153 & 227.788 & 1 & 0.000 & 10.101 & 7.480 & 13.639 \\
\hline Malig3 & 0.519 & 0.149 & 12.158 & 1 & 0.000 & 1.681 & 1.255 & 2.251 \\
\hline Metabolic & 0.950 & 0.133 & 50.770 & 1 & 0.000 & 2.585 & 1.991 & 3.357 \\
\hline Miscel1 & 1.411 & 0.101 & 196.502 & 1 & 0.000 & 4.100 & 3.366 & 4.994 \\
\hline Miscel2 & -2.005 & 0.219 & 83.763 & 1 & 0.000 & 0.135 & 0.088 & 0.207 \\
\hline Neuro1 & -0.367 & 0.116 & 9.957 & 1 & 0.002 & 0.693 & 0.552 & 0.870 \\
\hline Neuro 2 & -0.414 & 0.081 & 25.973 & 1 & 0.000 & 0.661 & 0.564 & 0.775 \\
\hline Renal & -0.782 & 0.125 & 38.876 & 1 & 0.000 & 0.457 & 0.358 & 0.585 \\
\hline Resp 1 & 0.186 & 0.085 & 4.774 & 1 & 0.029 & 1.205 & 1.019 & 1.424 \\
\hline Resp 2 & -0.831 & 0.087 & 92.210 & 1 & 0.000 & 0.436 & 0.368 & 0.516 \\
\hline Resp 3 & -0.009 & 0.104 & 0.008 & 1 & 0.928 & 0.991 & 0.808 & 1.215 \\
\hline Trauma1 & 1.117 & 0.173 & 41.868 & 1 & 0.000 & 3.054 & 2.178 & 4.284 \\
\hline Trauma2 & -1.164 & 0.105 & 122.973 & 1 & 0.000 & 0.312 & 0.254 & 0.384 \\
\hline Constant & -2.322 & 0.094 & 607.218 & 1 & 0.000 & 0.098 & & \\
\hline
\end{tabular}


Appendix 4: Standardized mortality ratios of SHSMR diagnoses categories

\begin{tabular}{|l|l|l|l|l|l|l|l|l|l|}
\hline $\begin{array}{l}\text { Diagnoses } \\
\text { Group }\end{array}$ & $\begin{array}{l}\text { Jan.- } \\
\text { Mar. }\end{array}$ & $\begin{array}{l}\text { Apr.- } \\
\text { June }\end{array}$ & $\begin{array}{l}\text { July- } \\
\text { Sept. }\end{array}$ & $\begin{array}{l}\text { Oct.- } \\
\text { Dec. }\end{array}$ & $\begin{array}{l}\text { Diagnoses } \\
\text { Group }\end{array}$ & $\begin{array}{l}\text { Jan.- } \\
\text { Mar. }\end{array}$ & $\begin{array}{l}\text { Apr.- } \\
\text { June }\end{array}$ & $\begin{array}{l}\text { July- } \\
\text { Sept. }\end{array}$ & $\begin{array}{l}\text { Oct.- } \\
\text { Dec. }\end{array}$ \\
\hline Cerebrovasc1 & 97.8 & 92.9 & 102.6 & 90.4 & Malig3 & 104.1 & 106.5 & 95.3 & 110.1 \\
\hline Cerebrovasc2 & 98.3 & 98.7 & 100.5 & 97.2 & Metabolic & 70.6 & 98.4 & 111.5 & 110.5 \\
\hline CVS1 & 100.9 & 96.2 & 95.7 & 85.5 & Miscel1 & 100.9 & 139.3 & 128.8 & 0.0 \\
\hline CVS2 & 104.8 & 109.6 & 115.3 & 123.3 & Miscel2 & 237.7 & 0.0 & 203.9 & 0.0 \\
\hline CVS3 & 101.8 & 92.6 & 104.2 & 75.0 & Neuro 1 & 129.4 & 58.4 & 60.7 & 152.2 \\
\hline Gastro1 & 104.8 & 116.8 & 97.7 & 98.7 & Neuro 2 & 93.4 & 102.4 & 85.2 & 96.2 \\
\hline Gastro2 & 108.2 & 101.8 & 104.0 & 104.2 & Renal & 99.9 & 102.2 & 96.8 & 100.9 \\
\hline Gastro3 & 93.0 & 100.7 & 90.9 & 105.6 & Resp 1 & 65.1 & 92.0 & 126.5 & 124.7 \\
\hline Haem & 106.5 & 0.0 & 124.7 & 115.8 & Resp 2 & 97.3 & 101.6 & 90.5 & 88.0 \\
\hline Low risk & 89.4 & 91.1 & 122.4 & 31.5 & Resp 3 & 99.3 & 100.7 & 99.8 & 103.0 \\
\hline Malig1 & 99.2 & 87.2 & 97.1 & 106.5 & Trauma1 & 145.6 & 174.6 & 0.0 & 0.0 \\
\hline Malig2 & 94.7 & 104.4 & 105.1 & 84.6 & Trauma2 & 130.4 & 75.0 & 87.1 & 0.0 \\
\hline
\end{tabular}

